\title{
Pituitary abscess: a case report and review of the literature
}

\author{
Apostolos K A Karagiannis', Fotini Dimitropoulou', Athanasios Papatheodorou², \\ Stavroula Lyra ${ }^{2}$, Andreas Seretis ${ }^{3}$ and Andromachi Vryonidou' ${ }^{1}$
}

1Department of Endocrinology, Diabetes and Metabolism, 2Department of Radiology، Korgialeneio Benakeio EES, Peripheral General Hospital Athens, Athens, Greece, and

${ }^{3}$ Department of Neurosurgery, General Hospital of Athens 'G. Gennimatas', Athens, Greece
Correspondence should be addressed to A Vryonidou

Email

mahi_vr@hotmail.com

\section{Summary}

Pituitary abscess is a rare life-threating entity that is usually misdiagnosed as a pituitary tumor with a definite diagnosis only made postoperatively. Over the last several decades, advances in healthcare have led to a significant decrease in morbidity and mortality due to pituitary abscess. We report a case of a 34-year-old woman who was admitted to our department for investigation of a pituitary mass and with symptoms of pituitary dysfunction, headaches and impaired vision. During her admission, she developed meningitis-like symptoms and was treated with antibiotics. She eventually underwent transsphenoidal surgery for excision of the pituitary mass. A significant amount of pus was evident intraoperatively; however, no pathogen was isolated. Six months later, the patient was well and had full recovery of the anterior pituitary function. Her menses returned, and she was only on treatment with desmopressin for diabetes insipidus that developed postoperatively.

\section{Learning points:}

- Pituitary abscess is a rare disease and the reported clinical features vary mimicking other pituitary lesions.

- The diagnosis of pituitary abscess is often very difficult to make and rarely included in the differential.

- The histological findings of acute inflammatory infiltration confirm the diagnosis of pituitary abscess.

- Medical and surgical treatment is usually recommended upon diagnosis of a pituitary abscess.

\section{Background}

Pituitary abscess is a rare but life-threatening condition (1). It accounts for less than $1 \%$ of all pituitary lesions and has the same frequency in both males and females (2) (3). The exact pathogen remains unclear in a significant percent of cases. Its management is mainly surgical, while some cases have been treated only with antibiotics $(4,5)$. It may occur either de novo or as a result of hematogenous spread or spread from a contiguous focus of infection such as meningitis and sphenoiditis (1). Presurgical diagnosis is usually difficult due to the rarity of the condition and the nonspecific presentation; symptoms mimic other pituitary lesions (6).

Pituitary hormone deficiencies remain in the majority of patients following treatment, though no long-term follow-up data exist in the literature. Two recent small studies suggest that the most determining factor for the persistence of pituitary hormone deficiencies is the duration of symptoms before diagnosis $(7,8)$. 
Table 1 Endocrine laboratory values before surgery and during follow-up. Abnormal values at any time point are highlighted.

\begin{tabular}{l}
\hline Endocrine labs \\
\hline FSH $(\mathrm{mlU} / \mathrm{mL})$ \\
LH (mIU/mL) \\
Estradiol (pg/mL) \\
Prolactin (RI: $4-25 \mathrm{ng} / \mathrm{mL})$ \\
Free T4 (RI: $0.7-1.8 \mathrm{ng} / \mathrm{dL})$ \\
T3 (RI: $0.8-2.7 \mathrm{nmol} / \mathrm{L})$ \\
TSH (RI: $0.3-4.2 \mu \mathrm{IU} / \mathrm{mL})$ \\
ACTH (RI: $9-52 \mathrm{pg} / \mathrm{mL})$ \\
Cortisol (RI: $5-25 \mu \mathrm{g} / \mathrm{dL})$ \\
DHEAS (RI: $35-350 \mathrm{ng} / \mathrm{mL})$ \\
T. Testo (RI: $0.1-0.8 \mathrm{ng} / \mathrm{mL})$ \\
IGF $1(\mathrm{RI}$ for $25-39-\mathrm{year}$ old: \\
180-499 ng/mL)
\end{tabular}

\begin{tabular}{ccc} 
Before surgery & & 1 month after surgery \\
\cline { 1 - 1 } 2.6 & & 5.4 \\
2.7 & 3.2 \\
36 & 32 \\
$\mathbf{3 6}$ & $\mathbf{2 6}$ \\
0.86 & $14.4 \mathrm{pmol} / \mathrm{L}^{\mathrm{a}}$ \\
1.8 & 1.9 \\
$\mathbf{0 . 0 7}$ & 0.78 \\
24 & 26 \\
$\mathbf{2 . 6}$ & & 9.5 \\
108 & 90 \\
0.1 & 0.18 \\
207 & \\
\end{tabular}

\begin{tabular}{c}
2 months after surgery \\
\hline 6.0 \\
4.0 \\
38 \\
20 \\
1.1 \\
1.4 \\
1.6 \\
34 \\
16 \\
71 \\
0.4 \\
225
\end{tabular}

6 months after surgery

aNormal: 9-21 pmol/L.

\section{Case presentation}

A 34-year-old woman was referred to the Endocrinology Department by the neurologist for assessment of a pituitary lesion. Upon admission, the patient presented with an 8-month history of frontal and temporal headaches, which was not relieved by simple analgesia. During the last 3 months, she developed blurred vision, amenorrhea, weakness, polydipsia and polyuria.

She had no past medical history and was not taking any regular medication, other than simple analgesia for her headaches. She was a nonsmoker and did not drink any alcohol. Her menarche was at 13 years of age, and she had regular monthly menses up to 3 months before her presentation. She was married and had two healthy children. She had a family history of type 2 diabetes mellitus on her mother's side.

\section{Investigation}

On clinical examination, the patient was afebrile without any symptoms of generalized illness. Her body mass index (BMI) was $29.2 \mathrm{~kg} / \mathrm{m}^{2}$, blood pressure was $120 / 70 \mathrm{mmHg}$, and had a regular pulse at 72 heart beats per minute. There were no meningeal signs and no neurological or cranial nerve deficit. Breath sounds were normal and the abdomen was soft with no rashes or masses. The patient had mild hirsutism over the face and the abdomen. There was no galactorrhea, and secondary sexual characteristics were unremarkable.

Laboratory investigation including complete blood count, biochemical profile and inflammatory markers, including erythrocyte sedimentation rate and c-reactive protein (CRP) levels, were all within the normal range. A urinalysis indicated a urine-specific gravity of 1.008 and no signs of infection. Urinary excretion was 2 and $2.5 \mathrm{~L} / 24 \mathrm{~h}$. Hormonal evaluation revealed mildly elevated serum prolactin levels of $36 \mathrm{ng} / \mathrm{mL}$ (reference range 4-25), decreased serum thyroid-stimulating hormone (TSH) of $0.07 \mu \mathrm{IU} / \mathrm{mL}$ (normal: $0.3-4.2$ ) with normal free thyroxine (fT4) of $0.86 \mathrm{ng} / \mathrm{dL}$ (normal: 0.7-1.80), and a low morning serum cortisol of $2.6 \mu \mathrm{g} / \mathrm{dL}$ (5-25) with normal adrenocorticotropic hormone (ACTH) of 24 (normal: 9-52 pg/mL) (Table 1).

Visual evaluation with Goldman's perimeter revealed bitemporal hemianopsia.

A brain MRI organized by her neurologist showed a sellar mass measuring $2.3 \times 2.7 \times 2.1 \mathrm{~cm}$ with suprasellar extension. The lesion had slightly hypointense and hyperintense signals in T1W and T2W images, respectively (Fig. 1A and B). After administration of gadolinium, there was ring-enhancement appearance of the lesion on T1W images (Fig. 1C and D). The pituitary mass had smooth borders; it was not extending into the cavernous sinuses, but it was compressing the optic chiasm and the stalk. The patient was diagnosed with possible pituitary adenoma.

\section{Outcome and follow-up}

Hydrocortisone replacement therapy was initiated and the patient was referred for surgical intervention.

Fifteen days later, the patient was urgently admitted to the Neurology department of another hospital with meningitis-like symptoms. She was febrile and had neck stiffness. Examination of the cerebrospinal fluid (CSF) showed increased protein levels of $110 \mathrm{mg} / \mathrm{dL}$ (normal:15-45 mg/dL), low glucose levels of $32 \mathrm{mg} / \mathrm{dL}$ with serum glucose levels of $95 \mathrm{mg} / \mathrm{dL}$ (normal: 60\% of serum glucose levels) and high white cell count $\left(2.500 / \mathrm{mm}^{3}\right.$ 

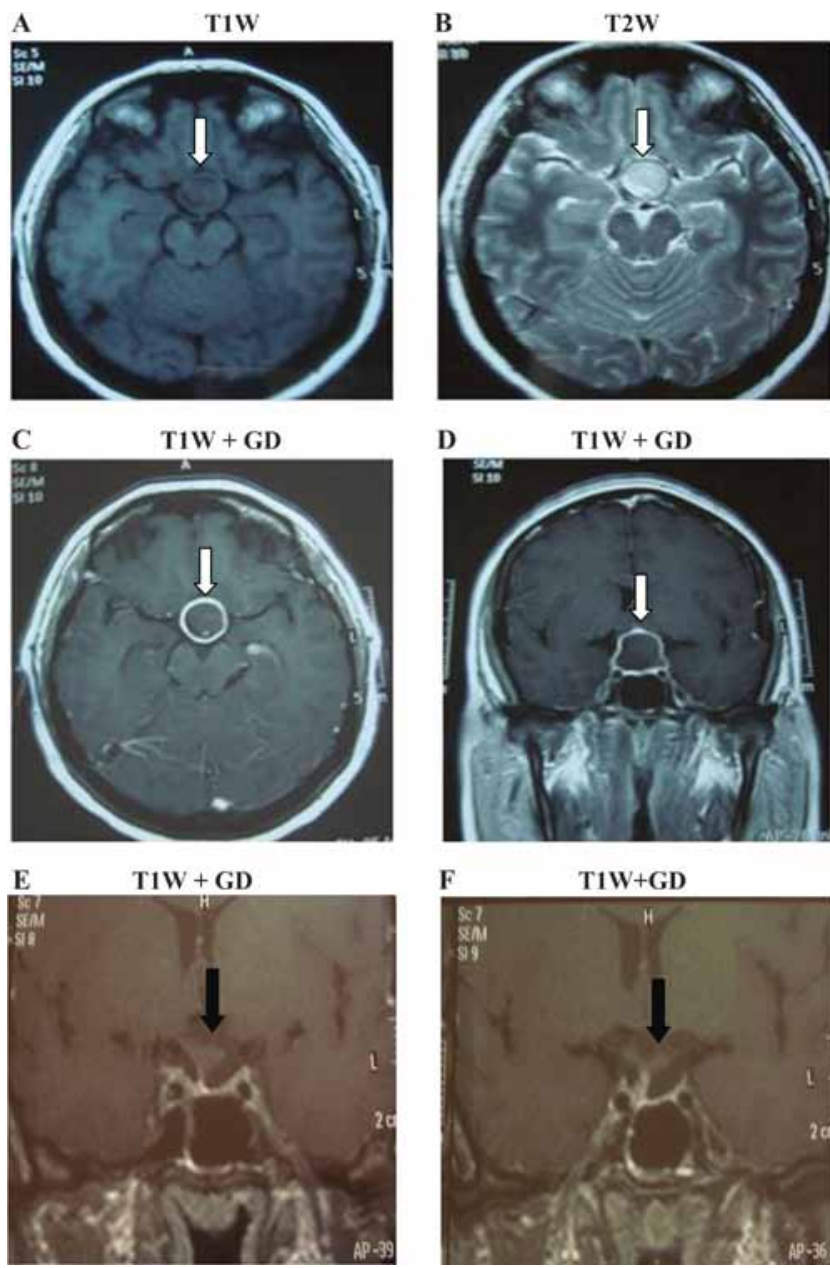

Figure 1

Pituitary abscess demonstrated in axial views (A) T1W, (B) T2W and (C) T1W images after administration of gadolinium as well as on sagittal view in (D) T1W after injection of gadolinium. The white arrow indicates the lesion. $\mathrm{E}$ and $\mathrm{F}$ represent sagittal sections of the pituitary after contrast administration 2 and 6 months after surgery, respectively. One can observe the empty sella turcica and the decompressed stalk (black arrows).

with $80 \%$ neutrophils). No pathogen was isolated from blood or CSF cultures, and empirical antibiotic therapy with intravenous ceftriaxone and ampicillin was started. A repeat brain MRI was performed which showed unchanged appearances of the presumed pituitary macroadenoma.

Thirty days following intravenous antibiotics, the patient had fully recovered and the neurosurgeon proceeded via transsphenoidal approach to the removal of the pituitary mass. Intraoperatively, there was a significant amount of yellowish pus, surrounded by fragments of fibrous tissue. The pus was drained and samples were sent for histological analysis and culture. Again, no pathogen was isolated and the pathology showed acute and chronic inflammatory infiltration consisting of $\mathrm{T}$ and B lymphocytes, neutrophils and histiocytes.

Postoperatively, the patient was afebrile, but she developed polyurea ( $>6 \mathrm{~L}$ per day) and she was treated with desmopressin ( $60 \mu$ g orally thrice daily). Antibiotic treatment continued; the patient was treated with linezolid and meropenem for 1 month intravenously followed by linezolid $1200 \mathrm{mg}$ and moxifloxacin $400 \mathrm{mg}$ orally daily for another month.

One month after surgery, while on hydrocortisone replacement therapy, her morning cortisol was higher than preoperative values $(9.5 \mu \mathrm{g} / \mathrm{dL})$ but still not within the reference range (Table 1). Visual field examination was normal and there was no bitemporal hemianopsia. Two months later, the endocrine laboratory test results were all within the normal range (Table 1 ). The patient had fully recovered and regular menstrual cycles resumed. Hydrocortisone was discontinued and she was kept only on desmopressin twice a day; due to recurrence of polyurea every time, she omitted a dose. Repeat MRI scans demonstrated complete removal of the intrasellar mass and an empty sella turcica was revealed. In addition, the stalk was visualized and was slightly deviated to the right (Fig. 1E). Six months re-evaluation was compatible with a completely normal anterior pituitary function (Table 1) and unchanged MRI appearances (Fig. 1F).

\section{Discussion}

In this case report, we presented a rare case of a woman with pituitary abscess and meningitis-like symptoms who was successfully treated with surgery and a long course of antibiotics.

Our patient had symptoms of pituitary insufficiency before developing meningitis; therefore, it was assumed that the central nervous system infection occurred due to spread from the pituitary lesion. A possible explanation of this is the leakage of pus into the subarachnoid space $(6,9)$. However, the converse possibility has also been described, that is the direct spread of infection to the pituitary from a nearby focus, such as the sphenoid sinus or the cavernous sinus $(10,11,12)$.

Pituitary abscesses may occur de novo, such as in our patient, in a previously normal pituitary gland in $70 \%$ of cases (2). In addition, it can occur secondary to a pre-existing lesion such as craniopharyngioma, adenoma or Rathke's cleft cyst $(13,14)$. Other risk factors include immunosuppression, previous irradiation or surgical procedures to the pituitary gland (15). Of note, in $60 \%$ of cases, no obvious reason can be found (15). 
Table 2 Synopsis of clinical symptoms at presentation from the major case series in the bibliography.

\begin{tabular}{|c|c|c|c|c|c|c|c|c|}
\hline \multirow[b]{2}{*}{ Author } & \multirow[b]{2}{*}{ Country } & \multirow[b]{2}{*}{ Series $(n)$} & \multicolumn{6}{|c|}{ Frequency of clinical symptoms at presentation, $n(\%)$} \\
\hline & & & Headache & $\begin{array}{c}\text { Anterior } \\
\text { pituitary } \\
\text { dysfunction }\end{array}$ & $\begin{array}{l}\text { Diabetes } \\
\text { insipidus }\end{array}$ & $\begin{array}{c}\text { Visual } \\
\text { disturbances }\end{array}$ & Fever & Meningismus \\
\hline Zhang et al. (1) & China & 29 cases & $21(72.4 \%)$ & $\overline{19(65.5 \%)}$ & $12(41.4 \%)$ & $\overline{10(34.5 \%)}$ & $4(13.8 \%)$ & NR \\
\hline Liu et al. (15) & China & 33 cases & $23(69.7 \%)$ & $28(84.8 \%)$ & $23(69.7 \%)$ & $9(27.3 \%)$ & $6(18 \%)$ & NR \\
\hline Vates et al. (16) & USA & 24 cases & $22(91.7 \%)$ & $13(54.2 \%)$ & NR & $12(50 \%)$ & $8(33 \%)$ & $6(25 \%)$ \\
\hline Jain et al. (2) & India & 6 cases & $6(100 \%)$ & $4(66.7 \%)$ & NR & $6(100 \%)$ & $1(16.7 \%)$ & $1(16.7 \%)$ \\
\hline Domingue \& Wilson (17) & USA & 7 cases & $4(57 \%)$ & $4(57 \%)$ & $3(43 \%)$ & $4(57 \%)$ & $4(57 \%)$ & $4(57 \%)$ \\
\hline
\end{tabular}

NR, not reported.

The reported clinical features vary. Zhang et al., Liu et al. and Vates et al. published the three case series that included 29, 33 and 24 patients with pituitary abscess, respectively. Pooling the data from these studies showed that headache without a certain pattern is the most common symptom (70-92\%), followed by anterior pituitary dysfunction (54-85\%) due to the destruction and necrosis of the gland, central diabetes insipidus (41-70\%), visual disorders (27-50\%), slight or moderate fever (14-33\%), fever with signs of meningeal irritation (25\%), and nonspecific symptoms of systemic infection such as dizziness $(10 \%)(1,15,16)$. Interestingly, all 6 cases in the series by Jain et al. presented with headache and visual disturbances, while Domingue et al. reported fever and meningism in $57 \%$ of patients $(2,17)$ (Table 2 ).

The most commonly isolated pathogens are Staphylococcus spp. and Streptococcus spp., followed by Neisseria spp., Micrococcus, Citrobacter spp., Escherichia coli, Brucella, Salmonella, Corynebacterium and Mycobacterium (16). However, in immunosuppressed patients, Aspergillus, Candida and Histoplasma are the most frequent pathogens (18). In this case, no infectious agent was isolated, which may be due to previous antibiotic treatment.

Findings on computed tomography commonly include enlargement of the sella turcica and a welldefined low-attenuation rounded lesion demonstrating ring-enhancement (19). On MRI, the features are of a cystic lesion with iso- or hypointense signal on T1W images and iso- or hyperintense signal on T2W images (20). After gadolinium administration, the lesion demonstrates peripheral enhancement (15). Other conditions that should be included in the radiological differential are cystic pituitary masses such as Rathke's cleft cyst, arachnoid and dermoid cysts (21), metastases, glioblastoma multiforme, chronic hematoma and multiple sclerosis $(22,23)$. Notably, Rathke's cleft cyst may mimic a pituitary abscess (24).
Transsphenoidal excision (TSS) of the lesion with decompression of the sella is the most effective and safe approach for patients presenting with mass effect (25, 26). Visual abnormalities may resolve in all patients who suffered before surgery, according to Liu et al. and Zhang et al. $(1,15)$. However, TSS has several uncommon complications such as sphenoiditis, leakage of CSF, epistaxis, hematoma of sella turcica, thalamic ischemia, meningitis, injury of the carotid artery and palsy of VI cranial nerve $(14,27)$. Endocrinological complications of TSS include anterior hypopituitarism, diabetes insipidus and syndrome of inappropriate antidiuretic hormone secretion (SIADH) $(1,15)$. Craniotomy is an alternative approach but has fallen out of favor because is more invasive and has a greater complication rate including bleeding, CSF infection, and thus longer hospitalization. This procedure is mainly recommended for larger lesions with extensive suprasellar extension (14), where transsphenoidal surgery is ineffective.

Medical treatment includes antibiotic therapy, which should be given for about 4-6 weeks (28). Empirical treatment with ceftriaxone (14) is indicated while awaiting microbiology and histological confirmation. Hormone replacement therapy is administrated based on hormone deficits of the pituitary gland, including stress dose glucocorticoid therapy $(14,29)$. It is important to recognize this condition among patients presenting with sellar masses, as early diagnosis and treatment improve survival and endocrinological outcome.

Patients who suffer from pituitary abscess may eventually have a good quality of life, if they are diagnosed and treated early. The overall mortality dropped from 45 to $10 \%(1,30)$ depending upon pre-existing comorbidities as well as complications (e.g. meningitis). Regarding pituitary function, the likelihood of improvement is higher in patients with short duration of symptoms (7) and those with a primary abscess as opposed to secondary disease (an underlying sellar mass such as adenoma or 
Rathke's cleft cyst) (2). Patients should be followed up with MRI of pituitary, visual field examination and hormonal profile at 3, 6 and 12 months after surgery (15).

Recurrence rates vary, depending mainly on the nature of the abscess (primary or secondary). Liu et al. reported the highest rate of recurrence (13\%) (15), while in most other series, the rates are lower $(1,16,21)$. It transpires that the majority of relapses are associated with either an immunological defect or previous pituitary surgery (15).

In conclusion, this case report highlights the importance of early diagnosis and appropriate management of a pituitary abscess. The diagnosis in most cases is extremely difficult before surgery, due to overlapping clinical signs, symptoms, imaging and laboratory findings with other sellar lesions. Pituitary abscess should be included in the differential diagnosis of patients with headache or signs of pituitary dysfunction as well as patients with pituitary mass who develop signs of meningeal inflammation. Efficient surgical and medical management results in a lower mortality and a higher recovery of pituitary hormone function.

\section{Declaration of interest}

The authors declare that there is no conflict of interest that could be perceived as prejudicing the impartiality of the research reported.

\section{Funding}

This case report did not receive any specific grant from any funding agency in the public, commercial or not-for-profit sector.

\section{Patient consent}

Written informed consent was obtained from the patient for publication of the submitted article and accompanying images.

\section{Author contribution statement}

Apostolos K A Karagiannis wrote the case report in its entirety. Andromachi Vryonidou and the other authors critically revised the paper and approved the final manuscript for submission.

\section{References}

1 Zhang X, Sun J, Shen M, Shou X, Qiu H, Qiao N, Zhang N, Li S, Wang Y \& Zhao Y 2012 Diagnosis and minimally invasive surgery for the pituitary abscess: a review of twenty nine cases. Clinical Neurology and Neurosurgery 114 957-961. (doi:10.1016/j.clineuro.2012.02.020)

2 Jain KC, Varma A \& Mahapatra AK 1997 Pituitary abscess: a series of six cases. British Journal of Neurosurgery 11 139-143. (doi:10.1080/02688699746492)

3 Dutta P, Bhansali A, Singh P, Kotwal N, Pathak A \& Kumar Y 2006 Pituitary abscess: report of four cases and review of literature. Pituitary 9 267-273. (doi:10.1007/s11102-006-8327-z)
4 Dechambenoit G, Datie A, Grunitzky EK, Ba Zeze V, Boni N, Kakou M \& Santini JJ 1993 Pituitary abscess, treated by medication. Revue Neurologique 149 567-571.

5 Kaur A, Agrawal A \& Mittal M 2005 Presumed pituitary abscess without infectious source treated successfully with antibiotics alone. Journal of Neuro-Ophthalmology 25 185-188. (doi:10.1097/01. wno.0000177292.06727.9c)

6 Walia R, Bhansali A, Dutta P, Shanmugasundar G, Mukherjee KK, Upreti V \& Das A 2010 An uncommon cause of recurrent pyogenic meningitis: pituitary abscess. BMJ Case Reports $\mathbf{2 0 1 0}$ (doi:10.1136/ bcr.06.2009.1945)

7 Jin WS, Xu WG, Yin ZN, Li HM, Li J, Zhang XP \& Wang GL 2015 Endocrine dysfunction and follow-up outcomes in patients with pituitary abscess. Endocrine Practice 21 339-347. (doi:10.4158/EP14457.OR)

8 Wang L, Yao Y, Feng F, Deng K, Lian W, Li G, Wang R \& Xing B 2014 Pituitary abscess following transsphenoidal surgery: the experience of 12 cases from a single institution. Clinical Neurology and Neurosurgery 124 66-71. (doi:10.1016/j.clineuro.2014.06.028)

9 Ford J, Torres LF, Cox T \& Hayward R 1986 Recurrent sterile meningitis caused by a pituitary abscess. Postgraduate Medical Journal 62 929-931. (doi:10.1136/pgmj.62.732.929)

10 Sahjpaul RL \& Lee DH 1999 Infratentorial subdural empyema, pituitary abscess, and septic cavernous sinus thrombophlebitis secondary to paranasal sinusitis: case report. Neurosurgery 44 864-866. (doi:10.1097/00006123-199904000-00101)

11 Verdalle P, Roquet E, Hor F, Raynal M, Courtois A, Bauduceau B, Pharaboz C \& Poncet JL 1997 Pituitary abscess. A rare complication of sinusitis. Revue de Laryngologie Otologie Rhinologie 118 327-329.

12 Garea Garcia-Malvar MJ, Zurdo-De Pedro V, Arrese-Reganon I, Herrero-Agustin J \& Klein-Zampana CJ 2012 Acute meningitis as the presenting symptom of a pituitary abscess. Revue Neurologique $\mathbf{5 5}$ $574-575$.

13 Obrador S \& Blazquez MG 1972 Pituitary abscess in a craniopharyngioma. Case report. Journal of Neurosurgery 36 785-789. (doi:10.3171/jns.1972.36.6.0785)

14 Ciappetta P, Calace A, D’Urso PI \& De Candia N 2008 Endoscopic treatment of pituitary abscess: two case reports and literature review. Neurosurgical Review 31 237-246. (doi:10.1007/s10143-007-0096-2)

15 Liu F, Li G, Yao Y, Yang Y, Ma W, Li Y, Chen G \& Wang R 2011 Diagnosis and management of pituitary abscess: experiences from 33 cases. Clinical Endocrinology 74 79-88. (doi:10.1111/j.13652265.2010.03890.x)

16 Vates GE, Berger MS \& Wilson CB 2001 Diagnosis and management of pituitary abscess: a review of twenty-four cases. Journal of Neurosurgery 95 233-241. (doi:10.3171/jns.2001.95.2.0233)

17 Domingue JN \& Wilson CB 1977 Pituitary abscesses. Report of seven cases and review of the literature. Journal of Neurosurgery 46 601-608. (doi:10.3171/jns.1977.46.5.0601)

18 Iplikcioglu AC, Bek S, Bikmaz K, Ceylan D \& Gokduman CA 2004 Aspergillus pituitary abscess. Acta Neurochirurgica 146 521-524. (doi:10.1007/s00701-004-0256-x)

19 Hanel RA, Koerbel A, Prevedello DM, Moro MS \& Araujo JC 2002 Primary pituitary abscess: case report. Arquivos de Neuro-Psiquiatria 60 861-865. (doi:10.1590/S0004-282X2002000500033)

20 Danilowicz K, Sanz CF, Manavela M, Gomez RM \& Bruno OD 2008 Pituitary abscess: a report of two cases. Pituitary 11 89-92. (doi:10.1007/s11102-007-0033-y)

21 Altas M, Serefhan A, Silav G, Cerci A, Coscun KK \& Elmaci I 2013 Diagnosis and management of pituitary abscess: a case series and review of the literature. Turkish Neurosurgery 23 611-616. (doi:10.5137/1019-5149.JTN.7443-12.2)

22 Sam S \& Molitch ME 2005 The pituitary mass: diagnosis and management. Reviews in Endocrine and Metabolic Disorders 6 55-62. (doi:10.1007/s11154-005-5225-z)

23 Shuster A, Gunnarsson T, Sommer D \& Miller E 2010 Pituitary abscess: an unexpected diagnosis. Pediatric Radiology 40 219-222. (doi:10.1007/s00247-009-1435-y) 
24 Trifanescu R, Ansorge O, Wass JA, Grossman AB \& Karavitaki N 2012 Rathke's cleft cysts. Clinical Endocrinology 76 151-160. (doi:10.1111/ j.1365-2265.2011.04235.x)

25 De Divitiis E, Cappabianca P \& Cavallo LM 2002 Endoscopic transsphenoidal approach: adaptability of the procedure to different sellar lesions. Neurosurgery 51 699-705. (doi:10.1227/00006123200209000-00016)

26 Koutourousiou M, Kontogeorgos G \& Seretis A 2010 Non-adenomatous sellar lesions: experience of a single centre and review of the literature. Neurosurgical Review 33 465-476. (doi:10.1007/s10143-010-0263-8)

27 Sudhakar N, Ray A \& Vafidis JA 2004 Complications after transsphenoidal surgery: our experience and a review of the literature.
British Journal of Neurosurgery 18 507-512. (doi:10.1080/02688690400 012459a)

28 Carpinteri R, Patelli I, Casanueva FF \& Giustina A 2009 Pituitary tumours: inflammatory and granulomatous expansive lesions of the pituitary. Best Practice \& Research Clinical Endocrinology \& Metabolism 23 639-650. (doi:10.1016/ j.beem.2009.05.009)

29 Dalan R \& Leow MK 2008 Pituitary abscess: our experience with a case and a review of the literature. Pituitary 11 299-306. (doi:10.1007/s11102-007-0057-3)

30 Blackett PR, Bailey JD \& Hoffman HJ 1980 A pituitary abscess simulating an intrasellar tumor. Surgical Neurology $\mathbf{1 4}$ 129-131.

Received in final form 3 April 2016

Accepted 4 May 2016 